\title{
Triptolide inhibits viability and induces apoptosis in liver cancer cells through activation of the tumor suppressor gene p53
}

\author{
YAN-YAN SUN $^{1 *}$, LEI XIAO $^{1 *}$, DONG WANG $^{1}$, YAN-CHAO JI $^{1}$, YU-PENG YANG $^{1}$, RONG MA $^{2}$ and XI-HAI CHEN ${ }^{1}$ \\ ${ }^{1}$ Department of General Surgery, The Fourth Affiliated Hospital of Harbin Medical University, Harbin, \\ Heilongjiang 150001; ${ }^{2}$ Department of Gynecological Oncology, The Third Affiliated Hospital \\ of Harbin Medical University, Harbin, Heilongjiang 150040, P.R. China
}

Received October 16, 2016; Accepted December 23, 2016

DOI: 10.3892/ijo.2017.3850

\begin{abstract}
The present study investigated the effect of triptolide on viability and apoptosis along with underlying mechanism in liver cancer cells. CCK- 8 assay showed that triptolide treatment for $48 \mathrm{~h}$ significantly reduced the viability of HepG2 and QSG7701 cells at $50 \mu \mathrm{M}$ concentration. Annexin V-FITC and propidium iodide staining showed that triptolide treatment of HepG2 cells at $50 \mu \mathrm{M}$ concentrations induced apoptosis in $56.45 \%$ cells compared to only $2.36 \%$ cells in the control cultures. Western blot assay showed that treatment of HepG2 cells with $50 \mu \mathrm{M}$ concentration of triptolide significantly induced phosphorylation of p53 in a 2 h-treatment. Phosphorylation of histone H2A.X indicator of DNA damage was induced by triptolide treatment after $12 \mathrm{~h}$ in HepG 2 cells. The level of nuclear p53 in a 6 h-treatment with $0,10,20,30,40$ and $50 \mu \mathrm{M}$ concentration of triptolide was found to be $15.3,19.6,28.5,43.7,63.8$ and $91.5 \%$, respectively. Treatment of HepG 2 cells with triptolide at $50 \mu \mathrm{M}$ concentration caused a significant increase in the binding potential of p53 to DNA. Triptolide treatment of HepG2 cells caused a significant increase in the expression of p21, Bax and DR5 genes in HepG2 cells. It also increased the expression of miR-34b and miR-34c in HepG2 cells markedly. Treatment of HepG2 cells with p53 inhibitor, pifithrin- $\alpha$ prior to incubation with triptolide significantly prevented induction of cell apoptosis. Suppression of p53 expression by siRNA inhibited the expression of p53 as well as its target genes along with the prevention of apoptosis induction. In conclusion, triptolide inhibits viability and induces apoptosis in liver cancer cells through activation of the tumor suppressor gene p53. Thus, triptolide can be used for the treatment of liver cancer.
\end{abstract}

Correspondence to: Dr Yan-Yan Sun or Dr Xi-Hai Chen, Department of General Surgery, The Fourth Affiliated Hospital of Harbin Medical University, No. 37, Yiyuan Street, Nangang, Harbin, Heilongjiang 150001, P.R. China

E-mail: sunyanyan1234987@hotmail.com

E-mail: xianxi_an1@163.com

*Contributed equally

Key words: phosphorylation, inhibitor, indicator, histone, apoptosis

\section{Introduction}

Triptolide, one of the members from diterpenoid family is obtained during the phytochemical investigation of Tripterygium wilfordii Hook $F$ (1). It has a long history of use in traditional Chinese medicine for various diseases. Biological screening of triptolide has revealed its potential as anticancer agent, an immunosuppressor and as contraceptive (1-3). Triptolide treatment induces apoptosis in cancer cells through cytochrome $c$ transfer into the cytosol and inhibition of expression of anti-apoptotic proteins (4). The apoptotic proteins including caspases play a vital role in the induction of apoptosis in cancer cells leading to alteration in cell morphology and biochemical changes (5-8).

Hepatocellular carcinoma is a commonly detected cancer and the third leading cause of cancer related deaths throughout the world $(9,10)$. Studies have revealed that every year more than 600,000 new cases of primary liver cancer are detected $(9,10)$. Despite the improvement in the 5-year survival rate of liver cancer patients, the rate of prognosis of liver cancer patients is very low (11). Liver cancer because of resistance to currently available chemotherapeutics and radiotherapy easily shows metastasis in other tissues such as lungs, lymph nodes, bones and adrenal glands (12). Therefore, development of novel and effective treatment strategies for liver cancer is required.

Tumor suppressor gene (p53) controls the function of several other genes involved in various cellular processes such as apoptosis induction, arrest of cell cycle and repair of DNA damage (13-16). Thus, p53 is involved in the formation and progress of various types of cancer. Activation of p53 gene takes place during cell stress through phosphorylation. Among various activation sites available on p53 the most important site of its activation is the phosphorylation at serine-15 $(17,18)$. Studies have shown that during stress by oxidants and radiations p53 is phosphorylated which then induces cell apoptosis (19-21). On activation p53 induces the expression of various other genes such as p21 and Bax which are well known for their role in cellular apoptosis (22-25). Thus, activation of p53 in cancer cells can play an important role in the arrest of cancer development and progress. In the present study, effect of triptolide on the viability and apoptosis of HepG2 and QSG7701 liver cancer cells as well the underlying mechanism was investigated. The present study demonstrated that trip- 
tolide induced inhibition of liver cancer cell viability involving activation of the tumor suppressor gene p53.

\section{Materials and methods}

Cell culture and reagents. HepG2 and QSG7701 liver cancer cell lines were obtained from the American Type Culture Collection (ATCC; Manassas, VA, USA). The cells were maintained in Dulbecco's modified Eagle's medium (DMEM) containing $10 \%$ fetal bovine serum (FBS). Cell culture was carried out in a standard cell culture medium containing L-glutamine $(2 \mathrm{mM})$, streptomycin $(100 \mu \mathrm{g} / \mathrm{ml})$ and penicillin $(100 \mathrm{U} / \mathrm{ml})$ in an incubator with humidified $5 \% \mathrm{CO}_{2}$ and $95 \%$ air atmosphere. Triptolide was obtained from Sigma-Aldrich (St. Louis, MO, USA) and its stock solution in dimethyl sulfoxide (DMSO) was stored at $-10^{\circ} \mathrm{C}$. Pifithrin- $\alpha$ was obtained from Calbiochem (La Jolla, CA, USA).

Cell viability assay. Viability of HepG2 and QSG7701 cells was determined using a CCK-8 kit (Dojindo Molecular Technologies Inc., Rockville, MD, USA). HepG2 and QSG7701 cells were seeded at a density of $2 \times 10^{6}$ cells/well into 96-well plates and treated with $10-100 \mu \mathrm{M}$ concentrations of triptolide for $48 \mathrm{~h}$. After incubation, the CCK-8 solution (10 $\mu \mathrm{l})$ was added to each well of the plate and the plates were incubated in incubator at $37^{\circ} \mathrm{C}$ for $3 \mathrm{~h}$. Absorbance was recorded three times independently using a microplate reader (Bio-Rad Laboratories, Richmond, CA, USA) at $450 \mathrm{~nm}$.

Apoptosis analysis using fluorescent microscopy and flow cytometry. HepG 2 cells put into the tissue culture slides were allowed to undergo attachment for $48 \mathrm{~h}$. The cells were then treated with various concentrations of triptolide for $48 \mathrm{~h}$, washed with phosphate-buffered saline (PBS) and subsequently put into the $1 \mathrm{X}$ binding buffer $(500 \mu \mathrm{l})$. A total of $5 \mu \mathrm{l}$ each of Annexin V-FITC and propidium iodide were added into the plates and the cells were incubated under dark conditions for $5 \mathrm{~min}$. The plates were analyzed using flow cytometry (BD FACSCalibur; BD Biosciences, San Jose, CA, USA) to determine the apoptotic cells.

Western blot analysis. HepG2 cells after incubation with various concentrations of triptolide were harvested and then were washed with ice-cold PBS. The cells were treated with RIPA lysis buffer (Roche Diagnostics, Shanghai, China) under ice-cold conditions for $45 \mathrm{~min}$. The lysates were centrifuged at $12,000 \mathrm{rpm}$ for $15 \mathrm{~min}$ at $4^{\circ} \mathrm{C}$ to collect the supernatant. Bradford method was used for the determination of the protein concentration in lysate. The proteins were separated by electrophoresis using $8 \%$ SDS-polyacrylamide gel and subsequently were transferred to NC membrane (Millipore, Billerica, MA, USA). The membrane incubation was performed with $10 \%$ dry milk in TBST to block non-specific binding sites. The membrane incubation with primary antibodies against Bax, DR5, p53, p53, histone-H2A.X and p-H2A.X (Cell Signaling Technology, Danvers, MA, USA) was performed overnight. The membranes were then washed with PBS and were incubated with secondary antibodies for $1 \mathrm{~h}$. Expression of the desired proteins was examined using an ECL kit (Millipore) according to the instructions from the manufacturer. The bands were visualized using autoradiography with Hyperfilm (Millipore).

Isolation of nuclei. Into the culture plates (100 mm diameter) HepG 2 cells were seeded at a density of $2 \times 10^{6} /$ plate and grown to confluence. The cells were then treated with triptolide for different durations. The cells were collected, PBS washed and subjected to fractionation into separate nuclear and cytosolic fractions using kit from Qiagen (Valencia, CA, USA). The sample purity of the nucleus and cytosol was checked using Lamin B and GAPDH as markers, respectively.

Analysis of DNA binding potential. HepG2 cells seeded into the plates were treated with triptolide for analysis of DNA binding potential of p53. The nuclear fractions obtained as mentioned above were examined using the TransAM p53 kit according to the protocol provided by the manufacturer (Active Motif, Carlsbad, CA, USA).

RT-PCR assay. Following treatment with triptolide for different durations HepG2 cells were collected to isolate total cell RNA using Isogen (Nippon Gene, Co., Ltd., Tokyo, Japan). Incubation of the RNA with DNase I was carried out to digest DNA that was contaminated. The RNA samples were purified by extraction using phenol and precipitation in ethyl alcohol. Ready-To-Go RT-PCR Beads (Amersham Pharmacia Biotech, Uppsala, Sweden) were used for the preparation of cDNA. AmpliTaq Gold ${ }^{\circledR}$ DNA Polymerase, LD (Applied Biosystems, Foster City, CA, USA) was employed for CR of cDNA using the primers: p21, 5'-TTAGCAGCGGAACAAGGAGT-3' and 5'-ATTCAGCATTGTGGGAGGAG-3' upstream and downstream, respectively); Bax, 5'-ATCCAGGATCGAGCAG GGCG-3' and 5'-GGTTCTGATCAGTTCCGGCA-3'; DR5, 5'-AAGACCCTTGTGCTCGTTG-3' and 5'-TCACCTGAA TCACACCTGG-3'; GAPDH, 5'-TGAAGGTCGGAGTCAA CGGATTTGGGT-3' and 5'-CATGTGGGCCATGAGGTCC ACCAC-3'. Proteins were treated at $90^{\circ} \mathrm{C}$ for $15 \mathrm{~min}$ followed by amplification. Amplification of the cDNA was performed by the sequence of $94^{\circ} \mathrm{C}$ for $50 \mathrm{sec}, 55^{\circ} \mathrm{C}$ for $50 \mathrm{sec}$ and $72^{\circ} \mathrm{C}$ for $50 \mathrm{sec}$. Quenching of the reaction was done using elongation step at $75^{\circ} \mathrm{C}$ for $5 \mathrm{~min}$. The $2 \%$ agarose gel and ethidium stain was used for the analysis of PCR products.

ELISA assay for apoptosis analysis. HepG2 cells were seeded at a density of $2 \times 10^{6}$ into $60-\mathrm{mm}$ cultural dishes (Falcon) and allowed to attain confluence. The cells were then treated with triptolide for $48 \mathrm{~h}$. Following incubation, the cells were collected, washed with PBS and lysed. The Cell Death Detection ELISA Plus kit (Roche Diagnostics, Indianapolis, IN, USA) was used for the measurement of DNA degradation into the nucleosomal fragments.

p53 silencing using RNA. HepG2 cells seeded at a density of $2 \times 10^{6}$ into $60-\mathrm{mm}$ cultural dishes were subjected to incubation with RNA for silencing p53 in transfection reagent (Mirus Bio, Madison, WI, USA). The plates were incubated for $48 \mathrm{~h}$ and then treated with triptolide for $48 \mathrm{~h}$. After incubation, apoptosis induction in HepG2 cell cultures was analyzed using ELISA assay. Western blot assay was used to examine the expression of various proteins. 


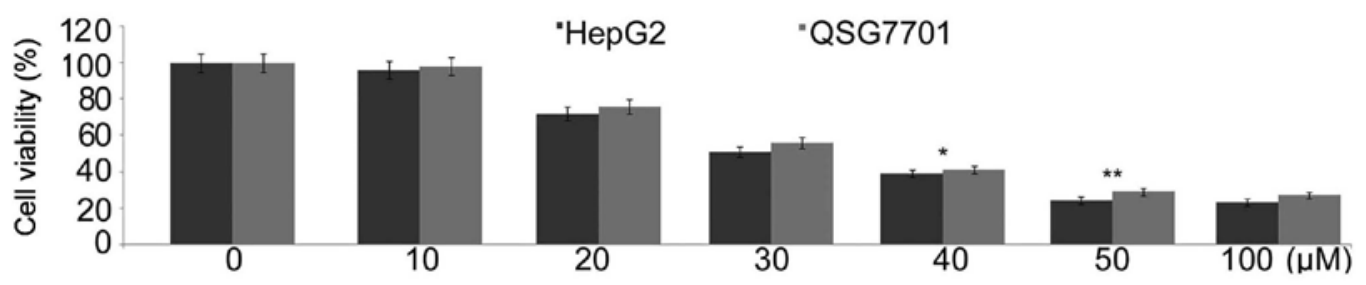

Figure 1. Triptolide treatment reduces viability of HepG2 and QSG7701 cells. The cells treated with various concentrations of triptolide for $48 \mathrm{~h}$ were subjected to MTT assay for analysis of cell viability. A concentration based reduction in viability was observed in HepG2 and QSG7701 cells at $48 \mathrm{~h}$ of treatment with triptolide. The expressed data are mean of three independently performed experiments. ${ }^{*} \mathrm{P}<0.05 ;{ }^{* *} \mathrm{P}<0.01$.

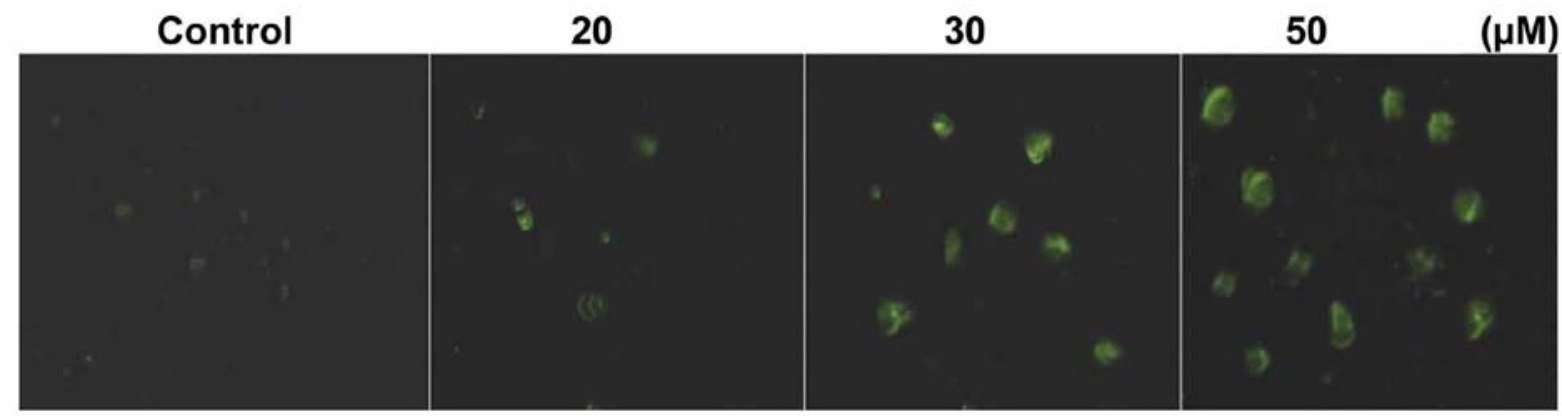

Figure 2. Triptolide treatment induces apoptosis in HepG2 cells. The cells treated with triptolide for $48 \mathrm{~h}$ were analyzed for apoptosis induction using Annexin V-FITC staining. The data presented are the mean of three experiments performed independently.

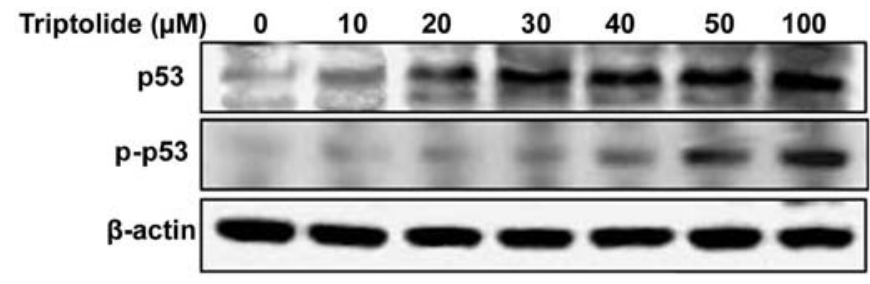

Figure 3. Triptolide treatment increases p53 phosphorylation in HepG2 cells. The cells seeded at a density of $2 \times 10^{6} /$ plate were incubated with various concentrations of triptolide for $48 \mathrm{~h}$. Following treatment, western blot assay was used for the analysis of 533 phosphorylation in HepG2 cells. The internal loading control was $\beta$-actin.

Statistical analysis. The data presented are the means \pm standard error or division of the mean (SEM or SD). Student's t-tests and two-way ANOVA were used for the analysis of the data using the statistical program in GraphPad Prism Version 4.0 (GraphPad Software, Inc., San Diego, CA, USA). All experiments were performed in triplicate. A $\mathrm{P}<0.05$ was taken to indicate statistically significant difference.

\section{Results}

Triptolide treatment inhibits HepG2 and QSG7701 cell growth and proliferation. In HepG2 and QSG7701 cells treatment with various doses of triptolide for $48 \mathrm{~h}$ caused a concentration-dependent proliferation reduction. Treatment with range of triptolide concentrations from 10 to $100 \mu \mathrm{M}$ led to a significant viability reduction at $50 \mu \mathrm{M}$ of $48 \mathrm{~h}$ treatment in both HepG2 and QSG7701 cell lines (Fig. 1).

Triptolide treatment of HepG2 cells induces apoptosis. Annexin V-FITC staining showed that triptolide treatment

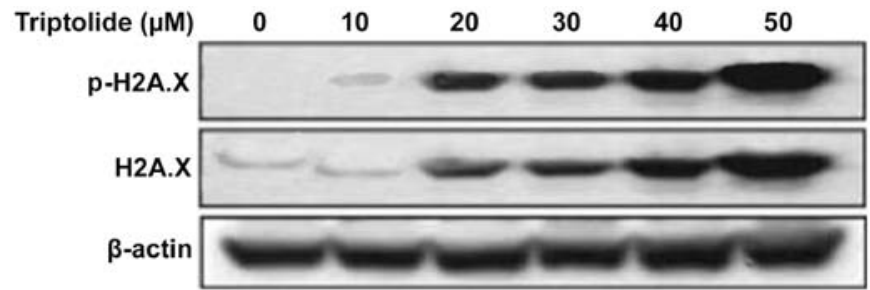

Figure 4. Effect of triptolide treatment on histone H2A.X phosphorylation HepG2 cells were treated with triptolide treatment for $48 \mathrm{~h}$ and the phosphorylation of histone H2A.X was analyzed using western blot assay.

of HepG2 cells for $48 \mathrm{~h}$ induced apoptosis. HepG2 cells were treated with 10-50 $\mu \mathrm{M}$ concentrations of triptolide for $48 \mathrm{~h}$ and then were analyzed by fluorescent microscopy. Triptolide treatment of HepG2 cells at $50 \mu \mathrm{M}$ concentrations induced apoptosis in $56.45 \%$ cells compared to only $2.36 \%$ cells in the control cultures (Fig. 2).

Triptolide increases tumor suppressor p53 phosphorylation. Treatment of HepG2 cells with triptolide at various concentrations induced phosphorylation of p53 at serine- 15 residue. The phosphorylation of p53 was significant at $2 \mathrm{~h}$ of treatment with $50 \mu \mathrm{M}$ concentration of triptolide in HepG2 cells (Fig. 3).

Phosphorylation at serine-15 of p53 in HepG2 cells by triptolide is independent of DNA damage signals. Analysis of the phosphorylation of histone H2A.X at serine 139, indicator of DNA damage showed a significant increase by triptolide treatment from $12 \mathrm{~h}$ in HepG2 cells. However, no significant increase in the phosphorylation of histone H2A.X was observed at $1 \mathrm{~h}$ of triptolide treatment (Fig. 4). 


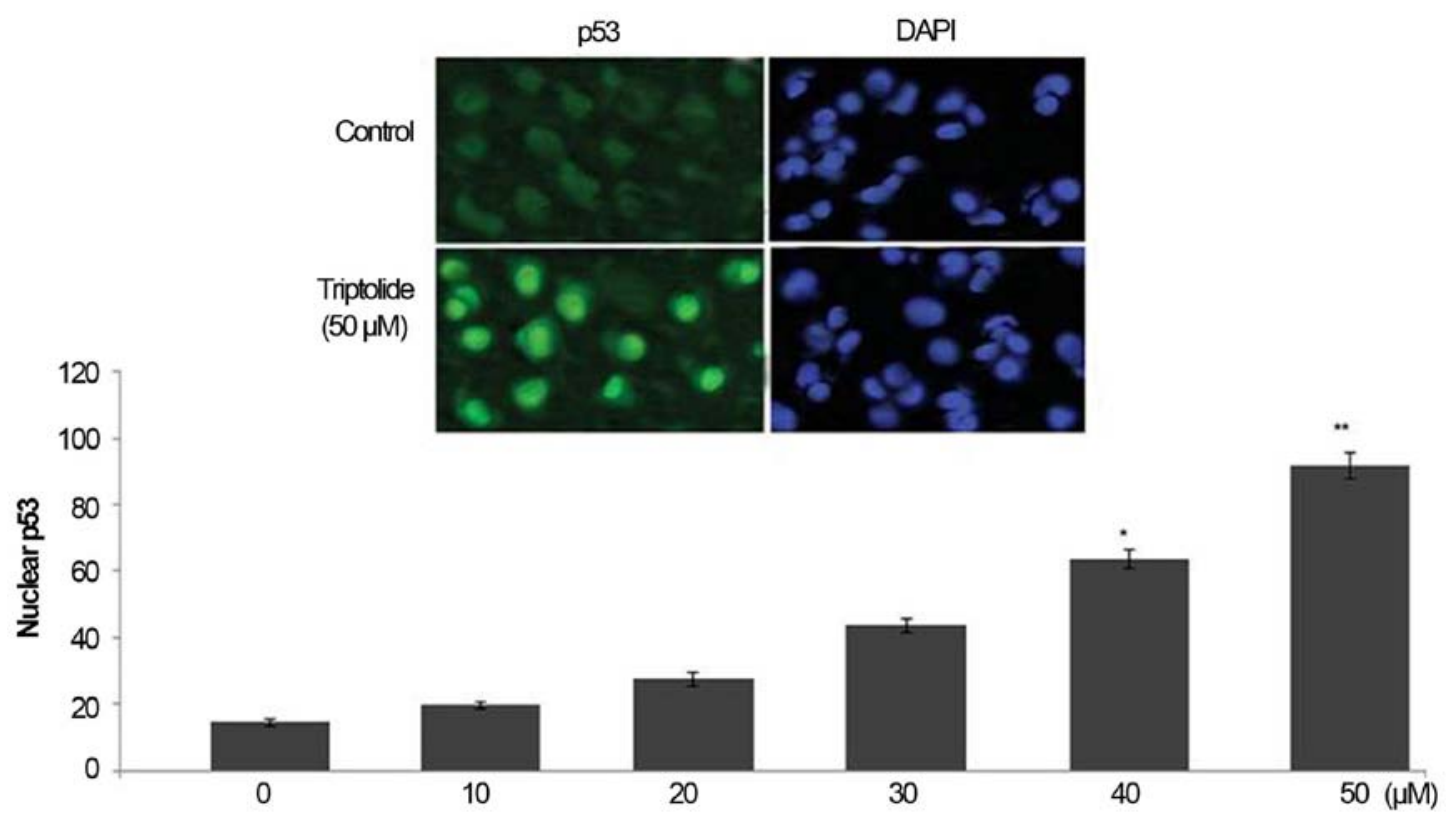

Figure 5. Effect of various concentrations of triptolide on expression levels of nuclear p53. HepG2 cell were treated with range of triptolide concentrations and stained with DAPI for examination of $\mathrm{p} 53$ expression. ${ }^{*} \mathrm{P}<0.05 ;{ }^{* *} \mathrm{P}<0.01$.

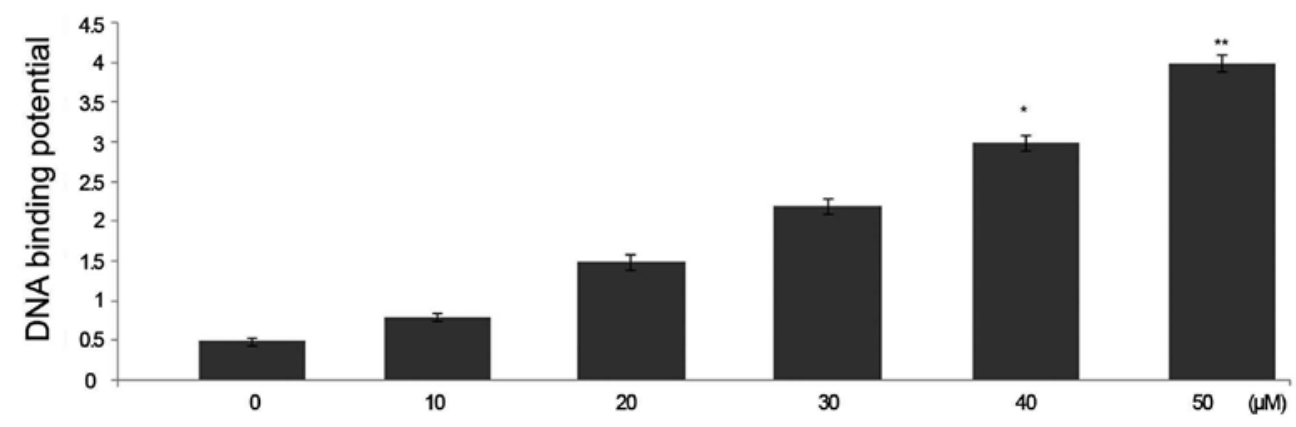

Figure 6. Triptolide treatment increases binding potential of 553 with DNA. HepG2 cells were treated with $50 \mu \mathrm{M}$ concentration of triptolide and then binding potential of p53 with DNA was examined using the TransAM-p53 kit. The cells after treatment with triptolide were fractioned into nuclear and cytosolic components. The nuclear protein $(4 \mu \mathrm{g})$ was used for measurement of binding of nuclear p53 with the consensus DNA sequence using the TransAM-p53 kit according to the manufacturer's instructions. ${ }^{*} \mathrm{P}<0.05 ;{ }^{* *} \mathrm{P}<0.01$.

Triptolide treatment increases p53 level in HepG2 cell nuclei. Treatment of HepG2 cells with triptolide caused a significant increase in the level of p53 in HepG2 cell nuclei (Fig. 5). In 6 h-treatment with $0,10,20,30,40$ and $50 \mu \mathrm{M}$ concentration of triptolide the level of nuclear p53 was 15.3, 19.6, 28.5, 43.7, 63.8 and $91.5 \%$, respectively (Fig. 5).

Triptolide treatment increases nuclear p53 DNA-binding activity in HepG2 cells. Treatment of HepG2 cells with triptolide at $50 \mu \mathrm{M}$ concentration caused a significant increase in the binding potential of $\mathrm{p} 53$ to DNA. The binding potential of p53 to DNA was significantly higher in $6 \mathrm{~h}$ triptolide treatment (Fig. 6).

Treatment with triptolide induces rapid transcription of $p 53$ target genes in liver cancer cells. Triptolide treatment of HepG2 cells caused a significant increase in the expression of various genes such as p21, Bax and DR5 at $6 \mathrm{~h}$. Compared to control HepG2 cells the expression of p21, Bax and DR5 genes was markedly higher on treatment with $50 \mu \mathrm{M}$ concentration of triptolide (Fig. 7). In addition, triptolide treatment also increased the expression of miR-34b and miR-34c in HepG2 cells markedly (Fig. 7). However, no increase was observed in the expression levels of miR-34a in HepG2 cells on triptolide treatment (Fig. 7).

Inhibition of p53 prevents triptolide induced HepG2 cell apoptosis. Treatment of HepG2 cells with p53 inhibitor, pifithrin- $\alpha$ prior to incubation with triptolide significantly prevented induction of cell apoptosis (Fig. 8). Suppression of p53 expression by siRNA inhibited the expression of p53 as well as its target genes along with the prevention of apoptosis induction (Fig. 8).

\section{Discussion}

In the present study, triptolide treatment reduced viability and induced apoptosis in HepG2 liver cancer cells. The mecha- 


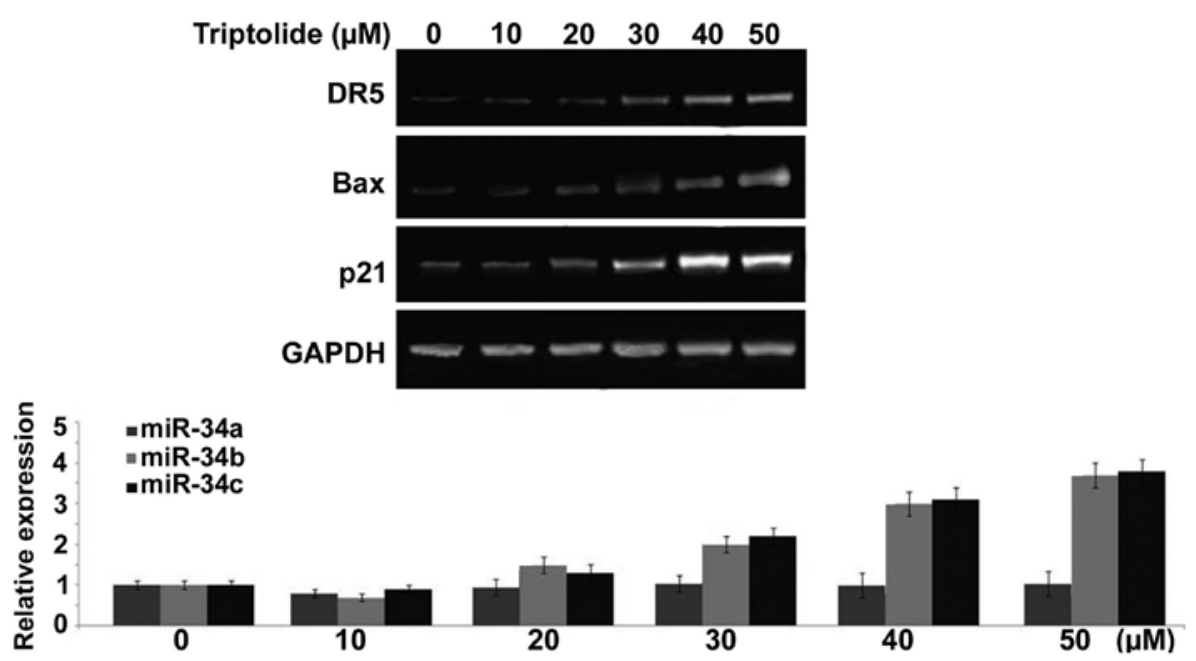

Figure 7. Effect of triptolide on p53 expression in HepG2 cells. The cells were treated triptolide for various time periods and then analyzed for the expression of p21, Bax and DR5 genes using RT-PCR assay. The cells after treatment with triptolide were analyzed for the expression of miR-34b, miR-34c and miR-34a genes.

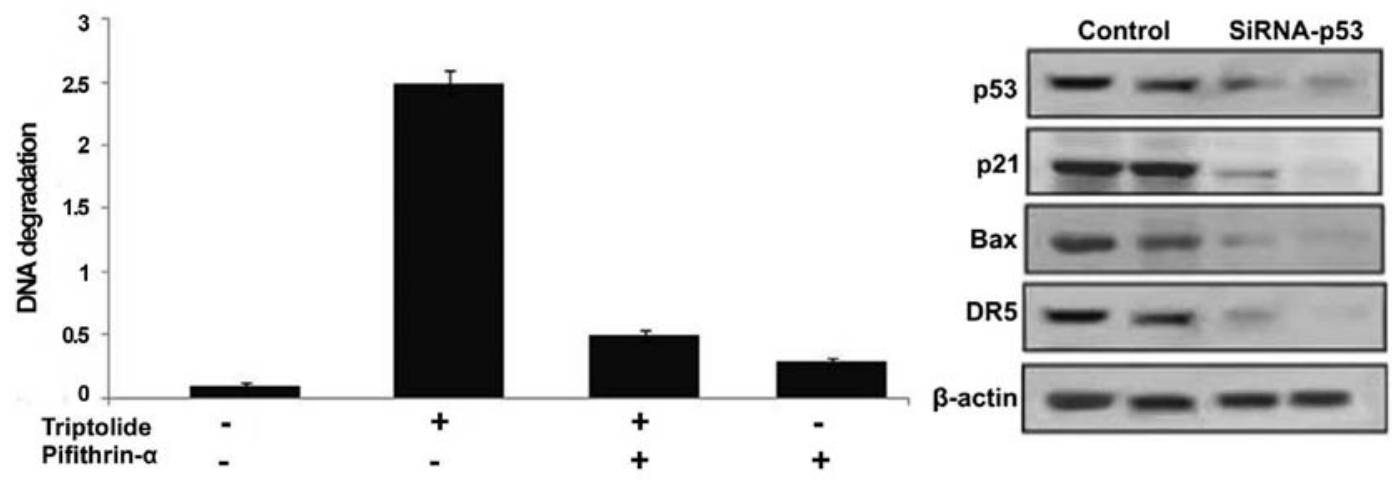

Figure 8. Suppression of p53 by pifithrin- $\alpha$ or siRNA inhibits triptolide-induced apoptosis. HepG2 cells were incubated for $24 \mathrm{~h}$ with $20 \mu \mathrm{M}$ concentration of pifithrin- $\alpha$ and then with $50 \mu \mathrm{M}$ concentration of triptolide for $48 \mathrm{~h}$. Following incubation ELISA was used for the analysis of induction of apoptosis in HepG2 cells. HepG2 cells were incubated for $48 \mathrm{~h}$ with p53-siRNA followed by treatment with triptolide for $48 \mathrm{~h}$. Western blot assay was used for analysis of expression of various proteins. Control, non-targeting siRNA.

nistic study revealed that triptolide exhibited its effect through activation of p53 tumor suppressor gene. Activation of p53 inhibits its interaction and subsequent degradation by MDM2 as well as increases the expression of nuclear p53 $(26,27)$. Various kinases have been found to activate $\mathrm{p} 53$ by phosphorylating it at serine-15 during stress $(28,29)$. Our results revealed that triptolide treatment of HepG2 cells at various concentrations induced phosphorylation of p53 at serine-15 residue. It is reported that activation of p53 can occur because of DNA damage signals as well during absence of these signals $(30,31)$. In the present study, analysis of the activation of histone H2A.X indicator of DNA damage revealed its phosphorylation in 6 h-treatment. However, phosphorylation of p53 was induced only after $2 \mathrm{~h}$ of treatment with triptolide in HepG2 cells. These findings revealed that activation of p53 in HepG2 cells by triptolide treatment is independent of the signals produced by DNA damage. Our results showed that triptolide treatment of HepG2 cells increased expression level of p53 by its transcription. The expression of activated $\mathrm{p} 53$ was found to be more in nuclear region of triptolide treated HepG2 cells. Following activation p53 binds with various gene promoters and induces their expression in the cells. Our results showed that triptolide treatment of HepG2 cells induced expression levels of p21, Bax and DR5 mRNAs. The expression level of miR-34b, miR-34c, and microRNAs in HepG2 cells was also increased on treatment with triptolide. In various types of cancers it has been found that miR-34a gene is deleted from its location in the chromosome (32). Our results showed that triptolide treatment of HepG2 cells induced no alteration in its expression. Different types of stresses are able to induce cancer cell apoptosis either in p53-dependent or -independent manner. In the present study, the role of p53 in induction of apoptosis by triptolide treatment was examined. The results from p53 suppression experiments revealed that p53 plays an important role in HepG2 cancer cell apoptosis induction on treatment with triptolide. The suppression of p53 by siRNA prevented induction of apoptosis in HepG2 cell cultures by triptolide treatment.

In conclusion, the present study demonstrated that triptolide inhibits viability and induces apoptosis in liver cancer cells through activation of tumor suppressor gene p53. Thus, triptolide can be used for the treatment of liver cancer. 


\section{References}

1. Zhen QS, Ye X and Wei ZJ: Recent progress in research on Tripterygium: A male antifertility plant. Contraception 51: 121-129, 1995

2. Tengchaisri T, Chawengkirttikul R, Rachaphaew N, Reutrakul V, Sangsuwan R and Sirisinha S: Antitumor activity of triptolide against cholangiocarcinoma growth in vitro and in hamsters. Cancer Lett 133: 169-175, 1998.

3. Hachida M, Lu H, Zhang X, Saito S, Furutani Y, Matsuoka R, Hoshi $\mathrm{H}$ and Koyanagi $\mathrm{H}$ : Inhibitory effect of triptolide on platelet derived growth factor-A and coronary arteriosclerosis after heart transplantation. Transplant Proc 31: 2719-2723, 1999.

4. Carter BZ, Mak DH, Schober WD, McQueen T, Harris D, Estrov Z, Evans RL and Andreeff M: Triptolide induces caspasedependent cell death mediated via the mitochondrial pathway in leukemic cells. Blood 108: 630-637, 2006.

5. Cohen JJ: Apoptosis. Immunol Today 14: 126-130, 1993.

6. White E: Life, death, and the pursuit of apoptosis. Genes Dev 10: $1-15,1996$.

7. Williams GT and Smith CA: Molecular regulation of apoptosis: Genetic controls on cell death. Cell 74: 777-779, 1993.

8. Wyllie AH, Kerr JF and Currie AR: Cell death: The significance of apoptosis. Int Rev Cytol 68: 251-306, 1980.

9. Ma S, Chan KW and Guan XY: In search of liver cancer stem cells. Stem Cell Rev 4: 179-192, 2008.

10. Tomuleasa C, Soritau O, Rus-Ciuca D, Pop T, Todea D, Mosteanu O, Pintea B, Foris V, Susman S, Kacsó G, et al: Isolation and characterization of hepatic cancer cells with stem-like properties from hepatocellular carcinoma. J Gastrointestin Liver Dis 19: 61-67, 2010.

11. Ricci-Vitiani L, Lombardi DG, Pilozzi E, Biffoni M, Todaro M, Peschle $C$ and De Maria R: Identification and expansion of human colon-cancer-initiating cells. Nature 445: 111-115, 2007.

12. Lee TK, Castilho A, Ma S and Ng IO: Liver cancer stem cells: Implications for a new therapeutic target. Liver Int 29: 955-965, 2009.

13. Vogelstein B, Lane D and Levine AJ: Surfing the p53 network. Nature 408: 307-310, 2000

14. Ma L, Wagner J, Rice JJ, Hu W, Levine AJ and Stolovitzky GA: A plausible model for the digital response of p53 to DNA damage. Proc Natl Acad Sci USA 102: 14266-14271, 2005.

15. Harris SL and Levine AJ: The p53 pathway: Positive and negative feedback loops. Oncogene 24: 2899-2908, 2005.

16. Levine AJ: p53, the cellular gatekeeper for growth and division. Cell 88: 323-331, 1997.

17. Bean LJ and Stark GR: Phosphorylation of serines 15 and 37 is necessary for efficient accumulation of $\mathrm{p} 53$ following irradiation with UV. Oncogene 20: 1076-1084, 2001.

18. She QB, Chen N and Dong Z: ERKs and p38 kinase phosphorylate $\mathrm{p} 53$ protein at serine 15 in response to UV radiation. J Biol Chem 275: 20444-20449, 2000.
19. Vazquez A, Bond EE, Levine AJ and Bond GL: The genetics of the p53 pathway, apoptosis and cancer therapy. Nat Rev Drug Discov 7: 979-987, 2008

20. Yin Y, Terauchi Y, Solomon GG, Aizawa S, Rangarajan PN, Yazaki Y, Kadowaki T and Barrett JC: Involvement of $\mathrm{p} 85$ in p53-dependent apoptotic response to oxidative stress. Nature 391: 707-710, 1998 .

21. Lowe SW, Ruley HE, Jacks T and Housman DE: p53-dependent apoptosis modulates the cytotoxicity of anticancer agents. Cell 74: 957-967, 1993.

22. Brugarolas J, Chandrasekaran C, Gordon JI, Beach D, Jacks T and Hannon GJ: Radiation-induced cell cycle arrest compromised by p21 deficiency. Nature 377: 552-557, 1995.

23. Miyashita T and Reed JC: Tumor suppressor p53 is a direct transcriptional activator of the human bax gene. Cell 80: 293-299, 1995.

24. Oda E, Ohki R, Murasawa H, Nemoto J, Shibue T, Yamashita T, Tokino T, Taniguchi T and Tanaka N: Noxa, a BH3-only member of the Bcl-2 family and candidate mediator of p53-induced apoptosis. Science 288: 1053-1058, 2000.

25. Yu J, Zhang L, Hwang PM, Kinzler KW and Vogelstein B: PUMA induces the rapid apoptosis of colorectal cancer cells. Mol Cell 7: 673-682, 2001.

26. Shieh SY, Ikeda M, Taya Y and Prives C: DNA damage-induced phosphorylation of p53 alleviates inhibition by MDM2. Cell 91: 325-334, 1997.

27. Prives C: Signaling to p53: Breaking the MDM2-p53 circuit. Cell 95: 5-8, 1998

28. Brew CT, Aronchik I, Hsu JC, Sheen JH, Dickson RB, Bjeldanes LF and Firestone GL: Indole-3-carbinol activates the ATM signaling pathway independent of DNA damage to stabilize p53 and induce G1 arrest of human mammary epithelial cells. Int J Cancer 118: 857-868, 2006.

29. Loehberg CR, Thompson T, Kastan MB, Maclean KH, Edwards DG, Kittrell FS, Medina D, Conneely OM and O'Malley BW: Ataxia telangiectasia-mutated and p53 are potential mediators of chloroquine-induced resistance to mammary carcinogenesis. Cancer Res 67: 12026-12033, 2007.

30. Jiang C, Hu H, Malewicz B, Wang Z and Lü J: Selenite-induced p53 Ser-15 phosphorylation and caspase-mediated apoptosis in LNCaP human prostate cancer cells. Mol Cancer Ther 3 : 877-884, 2004

31. Zhao R, Xiang N, Domann FE and Zhong W: Expression of p53 enhances selenite-induced superoxide production and apoptosis in human prostate cancer cells. Cancer Res 66: 2296-2304, 2006.

32. Chang TC, Wentzel EA, Kent OA, Ramachandran K, Mullendore M, Lee KH, Feldmann G, Yamakuchi M, Ferlito M, Lowenstein CJ, et al: Transactivation of miR-34a by p53 broadly influences gene expression and promotes apoptosis. Mol Cell 26 : $745-752,2007$. 